\title{
Biomethane production monitoring and data analysis based on the practical operation experiences of an innovative power-to-gas benchscale prototype
}

\author{
BOTOND SINÓROS-SZABÓ1 - MÁTÉ ZAVARKÓ1,2 - FELIX POPP3 - PAU \\ GRIMA $^{3}$ - ZOLTÁN CSEDÖ 1,2 \\ 1Power-to-Gas Hungary Kft., Szolnok, Hungary \\ ${ }^{2}$ Corvinus University of Budapest, Department of Management and \\ Organization, Budapest, Hungary \\ 3Electrochaea GmbH, Planegg, Germany \\ sinoros@p2g.hu
}

\begin{abstract}
Summary
Power-to-gas (P2G) is referred to technologies that convert carbon dioxide into methane. Both bio- and chemical catalysts may be used for conversion purposes. One of the most disruptive biotechnologies was developed by the University of Chicago (IL) (publication number: EP2661511B1), using a robust, highly selective, patented strain of Archaea. Electrochaea $\mathrm{GmbH}$ has developed an innovative bench-scale P2G prototype unit, which uses this highly efficient Archaea strain, specialized components and specifically developed control strategies. The structure and the components of the prototype are equivalent with the functional parts of the currently largest commercial scale biomethanation BioCat plant located in Avedøre, Denmark (www.biocat-project.com). Power-to-Gas Hungary $\mathrm{Kft}$. has committed to further develop this innovative technology. The first steps of this development have been taken by operating the benchscale unit and analyzing the data of the operating periods.

The prototype is operated based on weekly campaigns. During continuous operation, $\mathrm{H}_{2} \mathrm{O}$ is generated as a by-product of methane. Therefore, approximately $200 \mathrm{ml}$ of biocatalyst is discharged each day and concentrated media containing macro and micronutrients are injected into the reactor to maintain media composition. The laboratory staff records all gas composition data each morning. The gas composition is measured every 12 minutes by an Awite AwiFlex Cool+ gas analyzer. Within this article, we analyze the collected datasets containing more than 12000 records and present the first practical experiences of the operations of the innovative power-to-gas bench-scale prototype.

The analysis of the collected gas composition data of the product gas already provides important data for modelling the commercial-scaled processes. The average value of VVD was about $40 \mathrm{l} / \mathrm{l} / \mathrm{d}$ in the period under review. Further increase of the methane content can be achieved by introduction of higher mixing energy and by increasing pressure levels in the bioreactor (as demonstrated in the BioCat plant - data not shown here) - both of which are strategies envisioned for the commercial plant. In routine activities (turn on, shut down, continuous operation) we could verify the high robustness of the biocatalyst and the base connection between the registered datasets and performed test results.
\end{abstract}


Keywords: biomethane production, power-to-gas, prototype, monitoring and analysis

\section{Introduction}

Volatile weather conditions are unpredictable factors of renewable energy generation that require electric transmission system operators (TSOs) to change their strategies. The renewable electricity consumption and generation has to be balanced by the TSO at any given moment. Long- and short-term energy storage has become a key feature in the implementation of renewable energies. Since the EU and local governments have committed themselves to increase the rate of renewable energies, the increased share of electricity derived from renewable energies can be also anticipated. Different scenarios exist for ensuring that consumers have stable access to energy at all times. These include down-regulation of power generators, cross-border trade, storing, transformation of energy or the combination of the previous solutions.

The local and regional energy markets are all determined to reach the ambitious goal of transitioning energy industry to sustainability. In order to meet the climate protection targets fixed in the Paris Agreement on Climate Change, national governments are forced to strive for increasing the share of the renewables and decreasing carbon-dioxide $\left(\mathrm{CO}_{2}\right)$ emission in the same time. The most significant sources of $\mathrm{CO}_{2}$ output are the combustion of mineral oil and natural gas. Due to the "principle of progress" of the Paris Agreement and any scenarios of the Energy Roadmap 2050 - the decarbonisation of natural gas grids is inevitable.

The Power-to-gas (P2G) process can contribute to the achievement of both targets. This novel technology converts $\mathrm{CO}_{2}$ into methane $\left(\mathrm{CH}_{4}\right)$, the principle component of natural gas, by mixing hydrogen gas $\left(\mathrm{H}_{2}\right)$ and $\mathrm{CO}_{2}$ in a reactor, which contains either chemical or biological catalyst. Gas mixtures, such as flue gases of power plants or biogas derived from anaerobic digestion contain a significant $\mathrm{CO}_{2}$ content and can provide the carbon-dioxide source, while hydrogen can be gained from the electrolysis of water by using the surplus power from renewable energy generation. The produced gas then can be injected into the regional natural gas pipeline infrastructure and stored for months without losses (Fontaine et al., 2017).

In addition to the beneficial effect of decreasing greenhouse gases in the atmosphere and balancing the electric consumption and generation, P2G technologies can contribute to "Carbon Capture" ambitions such as Storing (CCS) and Utilization (CCU) and enable to sell surplus emission 
permits. The R\&D activities of P2G technology are essential since experts estimate the scale up of renewable gas (biomethane and renewable hydrogen) production in the EU may reach the quantity of 122 billion cubic meters by 2050 (van Melle et al., 2018).

As shown in Electrochaea's BioCat plant at Avedøre, DK, the feedstock can either be $\mathrm{CO}_{2}$ or raw biogas (a mixture of $\mathrm{CH}_{4}, \mathrm{CO}_{2}$ and possibly other components such as $\mathrm{H}_{2} \mathrm{~S}$ ) (data not shown in this study). The biogas is sourced from BioFos, DK the owner and operator of the wastewater treatment plant (WWTP) where the BioCat plant is located. In accordance to these experiences, raw biogas can be suitable feedstock for P2G technology. The combination of P2G with the operation of WWTPs is ideal since

- the biocatalyst is highly selective - it converts the $\mathrm{CO}_{2}$ component of the gas mixture and $\mathrm{CH} 4$ is considered as an inert gas in terms of $\mathrm{P} 2 \mathrm{G}$ conversion,

- contaminants (e.g. hydrogen sulfide) can be utilized as nutrients,

- there is the theoretical possibility to feed oxygen (the byproduct of electrolysis) back to the aeration system of the water treatment facility,

- both electrolysis and methane synthesis processes produce heat and the main product (biomethane) has more preferable features than electricity, thus P2G makes the widespread adapted combine heat and power plants (CHPs) redundant. (Electroachea.dk APS study, 2017)

The multi-purpose benchscale prototype adapting cutting-edge technology can contribute to significant R\&D activities, tests and onsite demonstrations and trainings. The ultimate objective is to acquire all the knowledge that is required for the development of several commercialscaled P2G units in the upcoming years.

\section{Material and methods}

The power-to-gas prototype unit is located at a Hungarian power plant site. A laboratory, wherein the prototype unit was deployed, was established inside the main premises of the building. The components of the benchscale, mobile prototype are shown in Figure 1.

The applied power-to-gas process consists of two phases: power-tohydrogen and hydrogen-to-methane (methanisation). The end product is biomethane. The methanation process is provided by a proprietary biocatalyst, an optimized strain of Archaea (Methanothermobacter thermautotrophicus). The robust, highly selective and efficient strain was developed by Prof. Laurens Mets at the University of Chicago (IL) (Mets, 2012). The high conversion efficiency of the strain is based on the fact that it converts only 1 out of 25 of $\mathrm{CO}_{2}$ molecules to cellular material. 
Figure 1. Main component units of the benchscale prototype (2018)

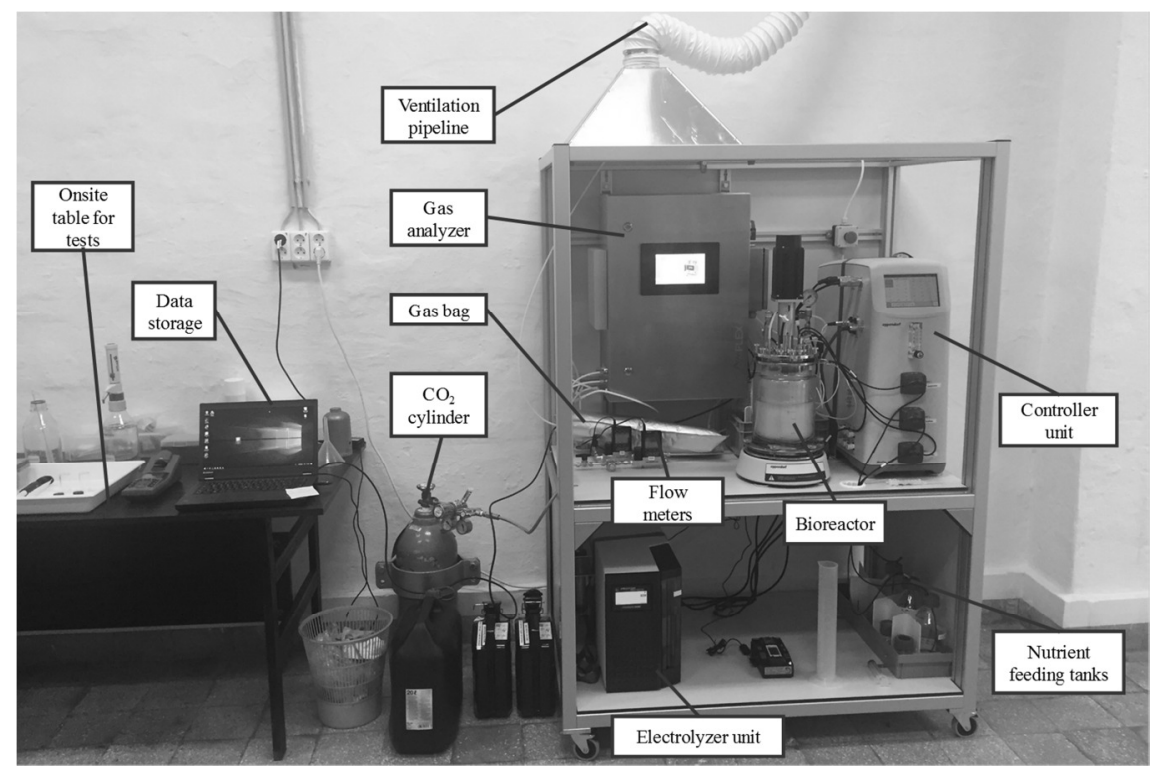

The conversion is carried out by basic reactions and mediated by the biocatalyst employing a unique set of enzymes (Ferry, 1998):

- Power-to-hydrogen: $4 \mathrm{H}_{2} \mathrm{O} \rightarrow 4 \mathrm{H}_{2}+2 \mathrm{O}_{2}+\mathrm{Heat}$ (electrolyzer),

- Hydrogen-to-methane: $\mathrm{CO}_{2}+4 \mathrm{H}_{2} \rightarrow \mathrm{CH}_{4}+2 \mathrm{H}_{2} \mathrm{O}$ (biocatalyst).

The stoichiometry of the second reaction requires four moles of hydrogen and one mole of carbon dioxide to yield one mole of methane.

The first reaction is provided by a Proton G600 polymer electrolyte membrane (PEM) electrolyzer. The produced hydrogen is delivered at the pressure of 5.4 barg $_{\mathrm{g}}$ to one of the Alicat MC-Gas Mass-Flow Controller devices. $\mathrm{A} \mathrm{CO}_{2}$ cylinder serves as the carbon dioxide source and it is also delivered at the same pressure (5.4 barg) to a second gas mass-flow controller. The objectives of the flow controllers are to set the stoichiometric ratio of approximately $4: 1$ and to reduce gas pressures by 3-4 bar $_{\mathrm{g}}$. The standard set-point of the hydrogen and carbon dioxide gas flow controllers is $0.252 \mathrm{ml} \cdot \mathrm{min}^{-1}$ and $0.060 \mathrm{ml} \cdot \mathrm{min}^{-1}$, respectively. After mixing, the two gas components both gas streams are fed into a 2-liter Eppendorf continuous stirred tank reactor (CSTR). The reactor vessel contains an impeller, baffles, sparger, and lockable ports and septum for feeding nutrients and discharging the processed liquid. A water jacket is adapted in order to provide the constant temperature for the biocatalyst, while two built-in peristaltic pumps of the Eppendorf BioFlo 120 controller are used for feeding a nitrogen source and sodium sulfide 
solution into the reactor (Martin et al., 2013). Antifoam is also provided to the bioreactor regularly.

The Awite AwiFlex Cool+ gas analyzer unit carries out the gas measurements of $\mathrm{H}_{2}, \mathrm{CH}_{4}$ and $\mathrm{CO}_{2}$ concentration in the outlet gas. Due to the low-level flow rates of the feed and product gases a (buffer) gas bag is required for collecting, interim storage and feeding the gas into the analyzer unit. After finishing the gas analysis process, the produced gas mixture is removed from the room via ventilation.

The hydrogen-to-methane chemical reaction produces water, which has to be discharged periodically. Since the generated water cannot be separated, the nutrient containing solution (and some of the active biocatalyst) is also removed in this process. In order to reestablish the desired concentration of macronutrients and micronutrients, these are replaced in form of concentrated media via syringes. The solutions are added based on the generated water levels as described in Martin et al. (2013).

Regular measurements are carried out for monitoring the health of the living culture. After measuring the volume of the discharged substrate for evaluating the required volume of the concentrated media to be added, three tests are performed for determining the value of

- optical density (using WTW PhotoFlex STD),

- oxidation/reduction potential (ORP) (by using VWR ORP15 test pen),

- pH level (by using LLG Labware pH PEN).

Inside the reactor the reaction occurs rapidly (within seconds). The unit produces ca. $3.61 / \mathrm{h}$ methane at regular setups.

\section{Operation and analytical methods}

The prototype is operated and turned off in one-week long campaigns. Typically, the operation is scheduled every other week, which means that shut-down periods are 8 days. The unusual operations regime is explained by the endeavor of Power-to-Gas Hungary Kft. to set up realistic sets of operation circumstances. The unit is turned on Monday mornings and shut down on Friday afternoons. After making visual inspections, approximately $200 \mathrm{ml}$ of substrate is discharged each day and the media are injected into the reactor via one of the plastic septa.

The results of the tests are recorded in a table containing the following specifications:

- date,

- pH value,

- stirring $\operatorname{rpm}\left(\mathrm{s}^{-1}\right)$,

- ORP (V),

- OD $(\%)$, 
- $\mathrm{H}_{2}$ flow rate $\left(\mathrm{ml} \cdot \mathrm{min}^{-1}\right)$,

- $\mathrm{CO}_{2}$ flow rate $\left(\mathrm{ml} \cdot \mathrm{min}^{-1}\right)$,

- $\mathrm{CH}_{4}$ composition $(\%(\mathrm{~V} / \mathrm{V}))$,

- $\mathrm{H}_{2}$ composition $(\%(\mathrm{~V} / \mathrm{v}))$,

- $\mathrm{CO}_{2}$ composition (\% (V/V)),

- nitrogen source pump flow rate $\left(\mathrm{ml} \cdot \mathrm{min}^{-1}\right)$,

- sulfide pump flow rate $\left(\mathrm{ml} \cdot \mathrm{min}^{-1}\right)$,

- comments.

This article provides an in-depth analysis of the test result in the operations period of $15 / 4 / 2018-15 / 5 / 2018$, which was the first 30 -daylong period of the prototype operation. This period contained two full weeks of operation (15/04/2018-20/04/2018 and 02/05/2018-07/05/ 2018) and the first two days of the upcoming campaign. The operating campaigns were scheduled taking into consideration both national and private holidays - which explain the offset in the term of 01-02/05/2018 (Figure 2).

Figure 2. $\mathrm{CH}_{4}, \mathrm{CO}_{2}$ and $\mathrm{H}_{2}$ measurements at Power-to-Gas Hungary Kft.'s Laboratory in the period of 15/04/2018-15/05/2018

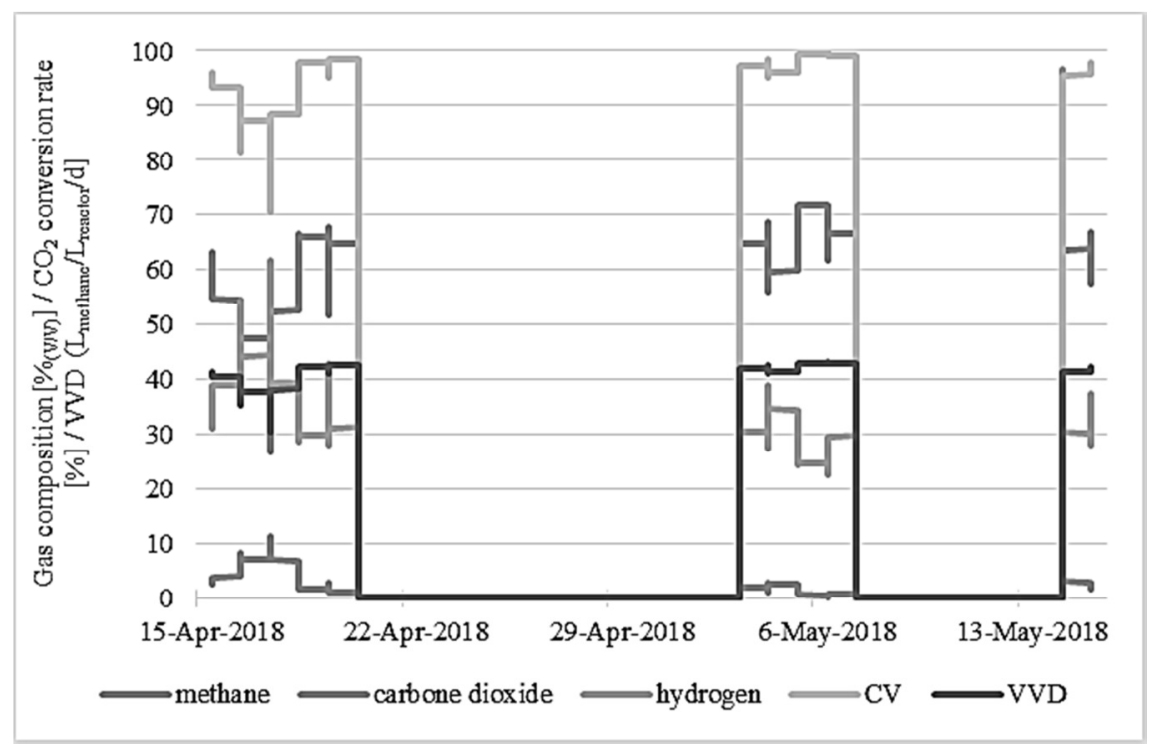

The laboratory staff recorded all the gas composition data once in every morning, while the analyzer is collecting the gas composition data every 12 minutes of the campaigns.

The "cold start" processes of the unit took place between 7:00-9:30 at the beginning of the campaigns and the shutdown protocol also required 
2.5 hours. The turn-on/heating up phase requires the timeframe of approx. 1-2 hours due to the heating requirements of the bioreactor liquid phase. The specific strain of Archaea requires an operating temperature of $62{ }^{\circ} \mathrm{C}$, which needs to be established via an integrated heater. Once the biocatalyst is active, heat removal is required due to the exothermic reaction catalyzed by the biocatalyst.

The data collection is started after 12:00 a.m., when the bioreactor has reached $62{ }^{\circ} \mathrm{C}$ and the flow-rates of $\mathrm{H}_{2}$ and $\mathrm{CO}_{2}$ have been adjusted according to protocol. The main values that describe the characteristics of the period under review are presented in Table 1.

Table 1. Main characteristic values of the P2G prototype measurements in the period of 15/04/2018-15/05/20181

\begin{tabular}{|c|c|c|c|c|c|}
\hline & Methane $^{1}$ & Carbon dioxide $^{1}$ & Hydrogen ${ }^{1}$ & $\mathrm{CV}^{1}$ & $\mathrm{VVD}^{3}$ \\
\hline Maximum value $^{2}$ & 71 & 11 & 61 & 99 & 43 \\
\hline Mean $^{2}$ & 59 & 3 & 34 & 94 & 40 \\
\hline Minimum value ${ }^{2}$ & 26 & 0.1 & 22 & 71 & 30 \\
\hline Standard deviation ${ }^{2}$ & 8 & 2 & 6 & 5 & 2 \\
\hline
\end{tabular}

Note: 1 - values in \%, 2 - flow rates: $\mathrm{CO}_{2}: 0.060 \mathrm{ml} \cdot \mathrm{min}^{-1}, \mathrm{H}_{2}: 0.252 \mathrm{ml} \cdot \mathrm{min}^{-1}$; 3: VVD in $1 / 1 /$ day

The maximum value of the methane composition in the period was over $71 \%(\mathrm{~V} / \mathrm{V})$ and the mean value is almost $60 \%$. Based on the record, in $88 \%$ of the cases the $\mathrm{CH}_{4}$ composition of the output gas exceeded the value of $50 \% \quad(\mathrm{~V} / \mathrm{V})$, while the $\mathrm{CO}_{2}$ composition went beyond the concentration of $7 \%(\mathrm{~V} / \mathrm{V})$ less than in the $10 \%$ of the cases only. The mean conversion rate of $\mathrm{CO}_{2}$ throughout the two campaigns was $94 \%$ and reached its maximum at $99 \%$. At the flows set in this experiment this corresponded to a volumetric methane production rate (VVD) of 43 $1 / 1 /$ day. The $\mathrm{H}_{2}$ content in the product gas is higher than required due to the over-stoichiometric provision of the $\mathrm{H}_{2}$ gas. In the next set of experiments, we will decrease the $\mathrm{H}_{2}$ flow to better represent the required 4:1 ratio of the two feed-gases. It is expected that the hydrogen content will be reduced in the product gas, while the $\mathrm{CO}_{2}$ content will stay at mean value of around $3 \%$ or less as long as the minimum of a $4: 1$ $\mathrm{H}_{2}: \mathrm{CO}_{2}$ ratio will be maintained. This will help to demonstrate that the product gas quality that can be achieved with the prototype is meeting grid gas quality. These results will help to justify the adaptability of the technology for producing biomethane in commercial-scaled plants that could meet the natural gas quality standards. The low $\mathrm{CO}_{2}$ content in the product gas already demonstrates the powerful conversion rate and efficacy of the biocatalyst. 
As the part of the everyday routine protocol ORP and OD is measured and registered. In the reviewed period, we obtained the following values:

- ORP: $-381.6 \pm 42.08 \mathrm{mV}$,

- OD: $22 \pm 3 \%$,

- Metabolic (produced/discharged) water: $251 \pm 92.67 \mathrm{ml}$, depending on methane generation.

Although the diagram sets of Figure 3 can provide insight on the characteristics of the processes in the period under review, we have to increase the resolution (by decreasing the visualization interval and the timeframe of our inspections).

Figure 3. Values of $\mathrm{CH}_{4}, \mathrm{CO}_{2}$ and $\mathrm{H}_{2}$ measurements at P2G Hungary Kft.'s Laboratory in the period of 03/05/2018-07/05/2018

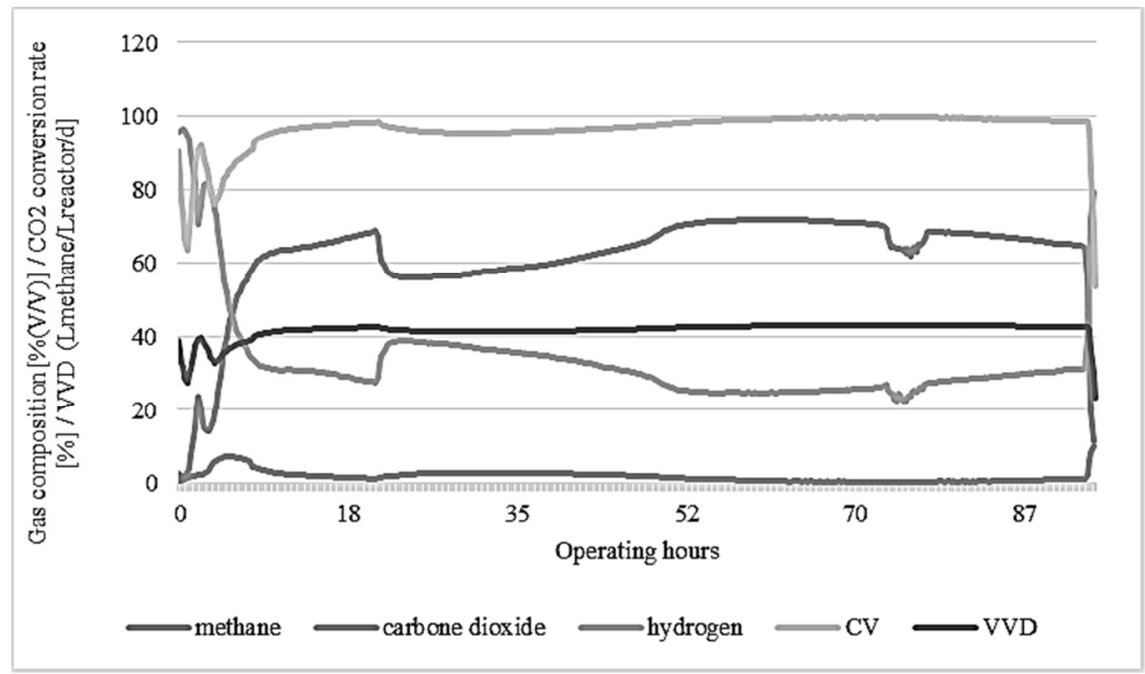

Figure 4 contains all the collected datasets of the produced gas composition in a daylong period. The diagram does not contain the value of $\mathrm{CO}_{2}$ concentration since it was nearly $0 \%(\mathrm{~V} / \mathrm{V})$, although the sum of the coherent data is less than $100 \%(\mathrm{~V} / \mathrm{V})$. The reason of this loss can be explained either by the presence of other components in the gas mixture, which is not evaluated by the analyzer unit or the inaccuracy of the measurement provided by the gas analyzer.

Despite the long downtime, the biocatalyst was able to convert the $\mathrm{CO}_{2}$ immediately. The launch of the start-up protocol took place at 9:30 a.m. For a shorter period of time there was a slight fallback in the methane conversion: at 10:30 a.m., the value of VVD was 40 1/1/d and that changed to $341 / 1 / \mathrm{d}$ by 11:00 a.m. The cause of this phenomenon was unknown. 
Figure 4. $\mathrm{CH}_{4}$ and $\mathrm{H}_{2}$ measurement at Power-to-Gas Hungary Kft.'s Laboratory on 06/05/2018

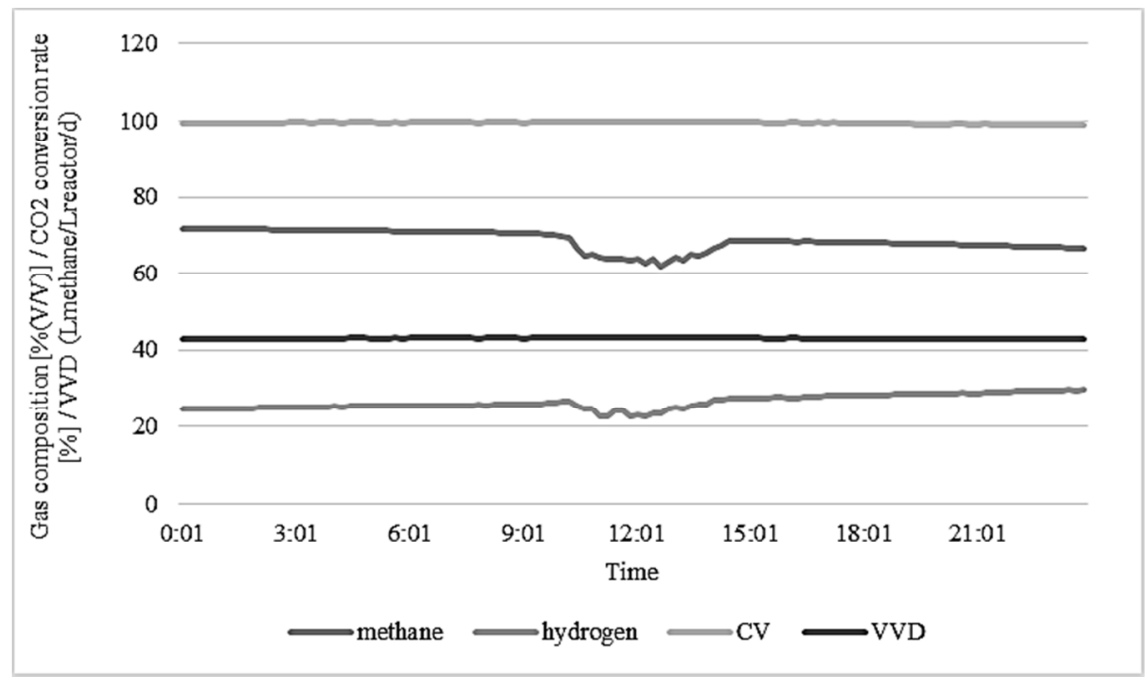

The nature of the $\mathrm{CH}_{4}$ composition diagrams can be considered as linear with a slight decrease in its value. The maximum value of VVD in the reviewed period was $43 \%$, which is outstandingly high compared to literature data (Luo and Angelidaki, 2012; Luo et al., 2012) to a reactor operated at low pressure. The curves in the diagrams represent the interruption in the operation since the activities of monitoring, discharging and feeding can be performed safely at non-operating circumstances.

The data collection period contained too many data records; therefore simplification was performed in the datasets. Groups of four-hour long periods were formed and the data records in each group were replaced by the mean value of the individual records. The result is shown in Figure 5.

The prototype was turned on at 9:00 a.m. on 03/05/2018. Since the gas bag was filled with hydrogen during the shutdown periods, the measured methane content initially was at a low level below 10\%, but rose rapidly when the unit was started and the biocatalyst immediately started converting $\mathrm{CO}_{2}$ to $\mathrm{CH}_{4}$. The first campaign provided the expected results: the maximum of the $\mathrm{CO}_{2}$ composition was below $1 \%(\mathrm{~V} / \mathrm{V})$ and hydrogen conversion rate was over $95 \%$ and was in line with the results provided by the BioCat project in Denmark (Fontaine et al., 2017). The average value of OD was 22 (measured at the wavelength of $610 \mathrm{~nm}$ ) regarding the whole period of the campaign, and ORP was between -320 $\mathrm{mV}$ and $-380 \mathrm{mV}$. 
Figure 5. $\mathrm{CH}_{4}, \mathrm{CO}_{2}$ and $\mathrm{H}_{2}$ measurement at Power-to-Gas Hungary Kft.'s Laboratory in the period of 03/05-15/05/2018

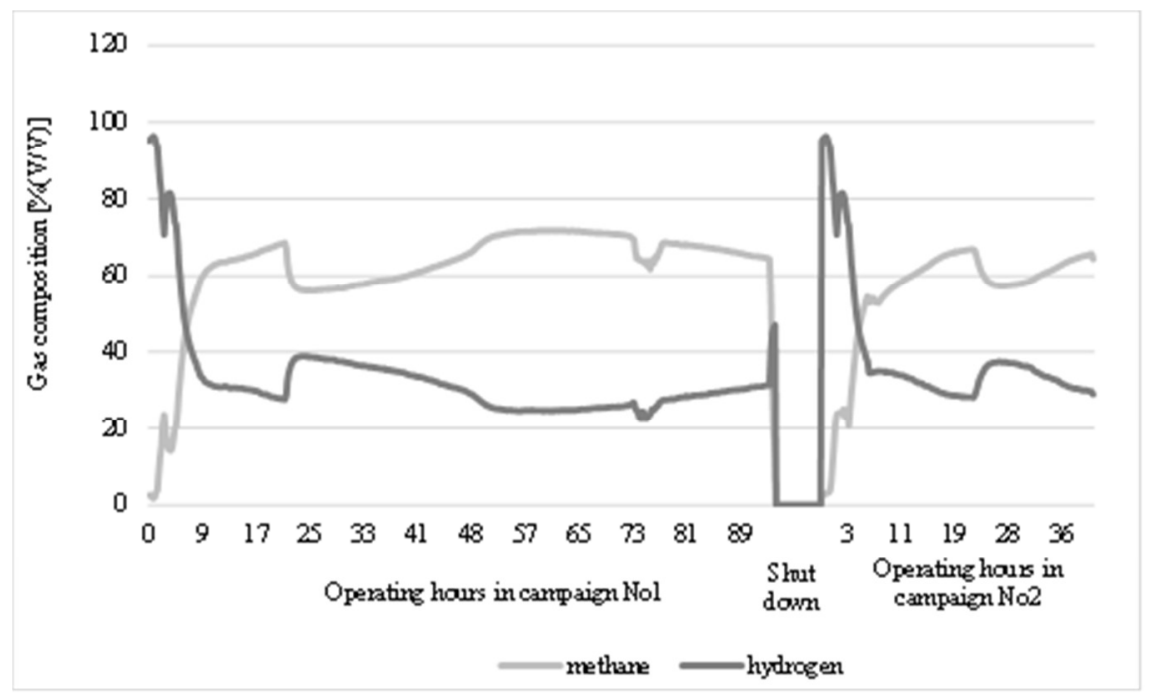

The second campaign (launched on 14/05/2018 at 8:30 a.m.) repeated the results and the expectations gained in the first campaign based on the similarity of the characteristics of the gas composition curves. After accomplishing the start-up protocol, the biocatalyst could provide a steady operation with no outages. A slight increase in the value of $\mathrm{OD}$ (from 22 to 30) was experienced only during the period of the reviewed campaigns. The repeatability of procedures could justify that the technology is robust and ready for scaling. The biocatalyst could supply the expected results in terms of gas composition rapidly within hours.

\section{Conclusions}

The overall components and set-up of the bench-scale prototype unit are matching the commercial-scaled BioCat plant in Denmark. Overall, the data sets generated with the bench-scale prototype are in line with the experience of BioCat (report study by Electroachaea.dk ApS, 2017). As shown in the current data set, the turn on/shut down cycles can be repeated with very similar outcome even if the prototype is shut down for several days. In order to clarify uncertainties, further examinations, tests and the reproduction of the phenomenon have to be performed in the future. The set of performed tests has to be extended with microscopic experiments as well. 
By analyzing the data collected via the gas analyzer and conducting manual tests we could state that the data from the prototype will be useful for modelling the commercial-scaled processes. The average value of methane composition CV and VVD was $60 \%(\mathrm{~V} / \mathrm{V}), 94 \%$, respectively and $401_{\text {methane }} / 1_{\text {reactor }} / \mathrm{d}$ in the period under review - the methane percentage can be further increased by reducing the gas flow of $\mathrm{H}_{2}$ to achieve a 4:1 ratio $\left(\mathrm{H}_{2}: \mathrm{CO}_{2}\right.$ ratio). Increasing the pressure in the reactor and increasing the invested energy (e.g. increasing the agitation speed) are additional measures to increase the overall productivity of a methanation reactor. In routine activities (turn on, shut down, continuous operation) we could identify the characteristics of the biocatalyst and the basic connection between the observed gas composition and the additional measured process parameters, such as $\mathrm{pH}$.

According to the experiences gained from the operation of the unit, the robustness of the technology was justified. Beside the robustness of the technology, the unit could reach its normal operational mode rapidly. These features could justify the applicability of the technology for transforming renewable energies to biomethane and the scaling-up of the prototype unit to commercial-scaled plants.

\section{Acknowledgements}

The authors would like to thank Hiventures Zrt./Kutatás-fejlesztési és Innovációs Állami Tókealap and Smart Future Lab Zrt./an incubator of MVM Group for their investment that enabled this research.

\section{References}

BioCat project (Power-to-gas via biological catalysis). Projectwebsite. http:/ / biocat-project.com/

Electroachea.dk ApS. (2017): Power-to-Gas via Biological Catalysis (P2G-Biocat). Project final report. https://energiforskning.dk/sites/energiteknologi.dk/ files/slutrapporter/12164_final_report_p2g_biocat.pdf

European Commission (2011): Energy Roadmap 2050. COM (2011) 885 final. Brussels.

Ferry, J. G. (1998): Enzymology of one-carbon metabolism in methanogenic pathways. FEMS Microbiol. 23: 13-38.

Fontaine, D.-Grima, P.-Hoerl, M.-Mets, L.-Forstmeier, M.-Hafenbradl, D. (2017): Power-to-Gas by Biomethanation - From Laboratory to Megawatt Scale. Communications in Agricultural and Applied Biological Sciences. Special Issue - Advances \& Trends in Biogas and Biorefineries. 82. 4: 183-187.

Luo, G.-Angelidaki, I. (2012): Integrated biogas upgrading and hydrogen utilization in an anaerobic reactor containing enriched hydrogenotrophic methanogenic culture. Biotechnology and Bioengineering. 109: 2729-2736. 
Luo, G.-Johansson, S.-Boe, K.-Xie, L.-Zhou, Q.-Angelidaki, I. (2012): Simultaneous hydrogen utilization and in situ biogas upgrading in an anaerobic reactor. Biotechnology and Bioeng. 109: 1088-1094.

Martin, M. R.-Fornero, J. J.-Stark, R.-Mets, L.-Angenent, L. T. (2013): A SingleCulture Bioprocess of Methanothermobacter thermautotrophicus to Upgrade Digester Biogas by $\mathrm{CO}_{2}$-to- $\mathrm{CH}_{4}$ Conversion with $\mathrm{H}_{2}$. Archaea. Article ID 157529.

Mets, L. (2012): Methanobacter Thermoautotrophicus Strain and Variants Thereof. Patent. Publication number: EP2661511B1.

van Melle, T.-Peters, D.-Cherkasky, J.-Wessels, R.-Ur, G.- Mir, R.-Hofsteenge, W. (2018): Gas for Climate - How gas can help to achieve the Paris Agreement target in an affordable way. Study published by Ecofys: 1-55. 